\title{
Exposure Studies of Different Kinds of Volatile Organic Compounds in Vapour Phase with a Narrow-gap Cell Containing $\mathrm{Cu}_{\mathrm{x}} \mathrm{S}$ Modified Carbon Microdisc Electrode
}

\author{
László Kiss ${ }^{1 *}$ \\ ${ }^{1}$ Department of General and Physical Chemistry, Faculty of Sciences, University of Pécs, H-7622 Pécs, Ifjúság street 6, Hungary \\ * Corresponding author, e-mail: kissl@gamma.ttk.pte.hu
}

Received: 16 December 2017, Accepted: 12 June 2018, Published online: 31 August 2018

\begin{abstract}
In this article, the feasibility of the $\mathrm{Cu}_{x} \mathrm{~S}$ modified carbon microdisc electrode was examined by exposure to four different volatile organic compounds (2-propanol, acetic acid, ethyl acetate and n-butylamine) directly in their vapour phase using cyclic voltammetry and amperometry. The performance of the modified microdisc was compared with the bare carbon microdisc ( $30 \mu \mathrm{m}$ in diameter) which was involved in a narrow-gap cell. By using both methods high current increase was observed for 2-propanol with the modified electrode and its sensitivity was sufficiently higher than with the bare electrode. The modified electrode showed lower current signals in case of acetic acid and n-butylamine. The latter formed a condensation layer at the interelectrode gap. Neither the bare nor the modified electrode was sensitive to ethyl acetate.
\end{abstract}

Keywords

copper sulphide, carbon microdisc, VOCs, amperometry, voltammetry

\section{Introduction}

Detection of volatile organic compounds (VOCs) in air has gaining importance in respect of health, safety both in the laboratories and industrial processes. Storage imperfections and spills cause strong evaporation of volatile chemicals therefore exposure to these hazardous materials poisons the biological systems. Many workers use larger quantity of volatile poisoning materials and continuous monitoring in their environment is necessary at certain sites.

Microelectrodes have been spread in different kinds of sensor applications due to the possibility of cell miniaturisation and ease of making narrow-gap cells. The reduction of the electrode size to the micrometer dimensions made the measurements possible also in low permittivity solvents in absence of supporting electrolyte. The increased mass transport to and from the electrode surface contributes to the rapid signal processing. They have favourable signal-to-noise ratio which can be further improved significantly with a suitable modifying layer. In this way, the enhancement of selectivity can be also reached.

Several works are reported in the literature concerning the detection of different organic compounds in air. Many works can be found concerning this problem published by Ghoroghchian et al. [1] and Brina and Pons [2], who carried out pioneering work in research of electrochemical VOC detection in air. For example, microelectrodes made from different materials were involved in mounted narrow-gap cells where the micrometre sized working electrode can be found on the tip [3] and these types of electrode assemblies are suitable for investigation of gases in non-aqueous liquids [4]. In concern of sensitivity the distance between the two electrodes proved oneself to be more dominant than the electrode material. In practise microdiscs are supplied with very thin insulating sheath and the counter / quasi reference electrode is deposited onto the insulating surface. Between the two electrodes there is an insulating gap (mainly epoxy) and its size is some tens of micrometers. In respect of the sensitivity the gap size was dominant and the materials of chemically inert electrodes were less important. Generally, the problem is in highly resistive media the significant ohmic drop. The signals are often difficult to distinguish between the different chemicals and due to the low current signals the background noise should be drastically reduced. In environmental conditions the large water content can 
also interfere with the signal. Bare microelectrodes are used mostly in the investigations, but surface modification might be necessary for example in case of gold to protect the surface with thiol compounds [3]. The resistance change of several materials is different upon exposure to specific compounds so many sensing methods are based on it. Therefore, chemiresistors are also widespread to detect series of organic compounds in air [6-13].

Copper sulphides $\left(\mathrm{Cu}_{\mathrm{x}} \mathrm{S}\right)$ are widely applied in many applications due to their semiconductive nature [14-21]. They are composed of $\mathrm{Cu}_{2} \mathrm{~S}$ and $\mathrm{CuS}$ and $x$ depends on their molar ratio. The black $\mathrm{CuS}$ is better semiconductor than $\mathrm{Cu}_{2} \mathrm{~S}$ which has shiny gray colour. In fuel cell studies the copper sulphide / carbon nanodot electrodes proved their excellent electrocatalytic property toward oxygen reduction [22]. The CuS nanoparticle modified glassy carbon electrode showed improved sensitivity in detection of glucose [23] and $\mathrm{H}_{2} \mathrm{O}_{2}$ [24] in aqueous solutions. In our earlier work the copper sulphide modifying layer was promising in electrooxidation of alcohols in hydrocarbon solvents [25].

In this work, the carbon microelectrode modified with $\mathrm{a} \mathrm{Cu}_{\mathrm{x}} \mathrm{S}$ layer was tested in the static exposures to four different types of VOCs: 2-propanol, acetic acid, ethyl acetate and $n$-butylamine and its performance was compared with the unmodified electrode. On the other hand, the bare and modified microdiscs were compared by a fixed interelectrode gap. The choice of carbon microdisc was fruitful as template because carbon is very cost effective compared with noble metals. It is chemically inert, electrochemically stable and its surface can be modified with a lot of materials.

\section{Experimental}

A Pt $\mid \mathrm{C}$ narrow-gap cell was fabricated from $100 \mu \mathrm{m}$ Pt wire (Goodfellow) and $30 \mu \mathrm{m}$ carbon fiber (Massachusetts, USA) and their length sections were put as close as possible to each other on an insulating plastic sheet and copper wires served as electric leads for the electrodes. They were glued to each other with silver epoxy to make electric contacts. The whole assembly was embedded in dental resin (Duracryl Plus, Spofa Dental a. s. Markova 238), and after hardening the two-electrode cell was formed. Then, it was sanded off perpendicularly to the length section of the electrodes and finally polished with $1 \mu \mathrm{m}$ alumina until two microdiscs were obtained close to each other having a $\sim 20 \mu \mathrm{m}$ insulating gap. Pt served as counter and quasi reference electrode and the carbon microdisc was the working electrode.
The used four liquids were analytical grade. 2-propanol was a Reanal product (Hungary), 99-100 \% acetic acid from Szkarabeusz (Hungary), ethyl acetate from Sigma Aldrich (USA) and $n$-butylamine from Alfa Aesar (USA). The water content was not removed from the vapour phase as one of the aim was to establish the applicability of the narrow-gap cell using amperometry and cyclic voltammetry in ambient conditions.

Humidity control measurements were conducted with the aid of a common humidity meter and percentage values of relative humidity $(\% \mathrm{RH})$ were used where water content was important. The additional influence of human activities were minimised during the exposure studies.

By the electrochemical measurements PalmSens potentiostat was used (Palm Instruments BV, Houten, The Netherlands) and for data acquisition a Pocket PC was connected to it. A hole (diameter $7 \mathrm{~mm}$ ) was drilled in the middle of a flat Plexiglas sheet. The thickness of the latter was $3 \mathrm{~mm}$. The size of the cell body was adjusted to the hole diameter and the cell was fixed in the hole with parafilm to avoid the leakage of vapour from the measuring volume. Before all exposure studies $\sim 1 \mathrm{~cm}^{3}$ of volatile solvent was placed onto the bottom of the vessels and then they were closed with even surface glass slides. The sheet containing the cell was fixed with a scaffold. The exposure studies were carried out in well-closed glass vessels where the Plexiglas sheet prevented also the vapor loss to the environment. A drawing about the setup used for the measurements can be seen in Fig. 1. Fifteen minutes were allowed for equilibration between liquid and vapour phase. After this equilibration time the glass slides were quickly removed and the vessels were put quickly under the cell. Finally, electrochemical experiments could be carried out in saturated vapor phases with all solvent, respectively.

By modifying the carbon surface with the $\mathrm{Cu}_{\mathrm{x}} \mathrm{S}$ layer a thin layer of copper was firstly deposited onto it. A $0.1 \mathrm{M}$ aqueous $\mathrm{CuSO}_{4}$ solution was used for the deposition and it

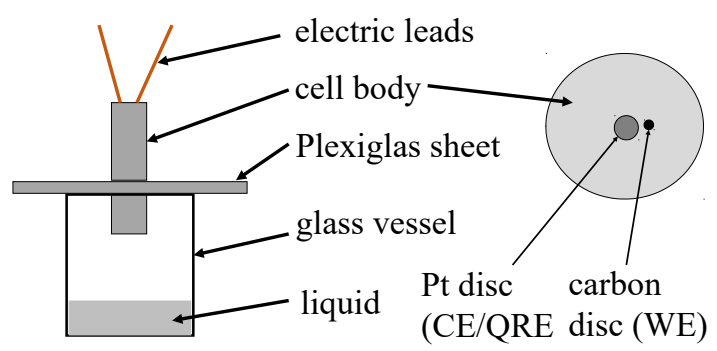

Fig. 1 Illustration of the measurement setup (the electrode arrangement is displayed on the right side) 
contained $0.1 \mathrm{M} \mathrm{H}_{2} \mathrm{SO}_{4}$ to prevent hydrolysis of metal ions. The oxygen was removed from the plating solution by purging it with nitrogen. This was a half cell which was connected through a salt-bridge to a $0.1 \mathrm{M} \mathrm{KCl} / \mathrm{AgCl} / \mathrm{Ag}$ reference electrode. For deposition of copper $-1 \mathrm{~V}$ vs. reference electrolyzing potential was applied. The electrolysis time was $20 \mathrm{~s}$ which was necessary for obtaining a thin metal deposit on the carbon microdisc. Then it was thoroughly washed with deionized water, activated in $0.1 \mathrm{M} \mathrm{HCl}$.

A sulfidizing solution was prepared dissolving $2 \mathrm{~g}$ of $\mathrm{Na}_{2} \mathrm{~S}$ (Merck, Germany) in $20 \mathrm{ml}$ of $0.1 \mathrm{M} \mathrm{HCl}$ for transforming the copper to $\mathrm{Cu}_{\mathrm{x}} \mathrm{S}$. Meanwhile, it was vigorously stirred with a magnetic stirrer and it was heated to $\sim 80^{\circ} \mathrm{C}$. Then, $0.1 \mathrm{~g}$ of sulphur powder was added to it. The heating was stopped when the solution became clear brownish yellow indicating that all of added sulphur dissolved in the form of polysulphide anions. The presence of elemental sulfur was necessary to increase the redox potential. However, the presence of sulphide ions in solution is sufficient for the metallic copper to undergo an oxidation reaction resulting copper sulphides. This solution composition ensured the transformation of as many copper as possible to $\mathrm{CuS}$ rather than $\mathrm{Cu}_{2} \mathrm{~S}$. In the presence of sulphide ions the following reaction takes place in acidic media:

$$
\begin{aligned}
& \mathrm{Cu}+\mathrm{S}^{2-}+2 \mathrm{H}^{+} \longrightarrow \mathrm{CuS}+\mathrm{H}_{2} \\
& \text { and } \mathrm{Cu}+\mathrm{H}_{2} \mathrm{~S} \longrightarrow \mathrm{CuS}+\mathrm{H}_{2} .
\end{aligned}
$$

As it can be seen from the equation, the oxidizing agents are the hydrogen ions in acidic solutions (in basic solution the $\mathrm{H}_{2} \mathrm{O}$ solvent) which reduces to molecular hydrogen. When elemental sulfur is present, another process can result $\mathrm{CuS}$ simultaneously to the previous reactions:

$$
\mathrm{Cu}+\mathrm{S} \longrightarrow \mathrm{CuS} \text {. }
$$

However, the standard potential of the $\mathrm{Cu}^{2+} / \mathrm{Cu}$ system is more positive $(+0.34 \mathrm{~V})$ than that of the $\mathrm{S} / \mathrm{S}^{2-}$ system $(-0.447 \mathrm{~V})$, taking into account the very low solubility of the precipitate $\mathrm{CuS}$ in water $\left(K_{s p}=8 * 10^{-37}\right.$ at $\left.298 \mathrm{~K}\right)$ the standard potential of the $\mathrm{CuS} / \mathrm{Cu}$ redox pair should be taken into account in the presence of sulphide ions $(-0.71 \mathrm{~V})$ which is a large negative shift from $+0.34 \mathrm{~V}$. This value clearly shows that the oxidization of metallic copper is possible according to the above reactions.

The part of cell containing the microdisc assembly was kept in the sulfidizing solution for $1 \mathrm{~min}$ and the deposited copper became $\mathrm{Cu}_{\mathrm{x}} \mathrm{S}$. The cell surface was rinsed again thoroughly with deionized water. Then, the cell was allowed to dry in a furnace at $60^{\circ} \mathrm{C}$. Finally, its surface was washed with $\mathrm{CS}_{2}$ to remove the traces of sulphur. With this procedure $\mathrm{CuS}$ was the prevalent in the sulphide layer as it was black which could be observed under microscope.

\section{Results and discussion}

\subsection{Voltammetric investigations}

In order to estimate the performance of the $\mathrm{Cu}_{\mathrm{x}} \mathrm{S}$ layer cyclic voltammetric studies were accomplished scanning between 0 and $2 \mathrm{~V}$ vs. Pt disc. The scan rate was $0.1 \mathrm{~V} / \mathrm{s}$ in all voltammetric experiments. Before all measurements, the cell was put into the saturated vapour for 15 minutes which was the rest time needed for equilibration between vapour and cell surface. Then, voltammograms were taken.

When voltammetric and amperometric experiments are carried out, the question is that what is responsible for the obtained current signals while there is no electrolyte between anode and cathode apart from the insulating plastic material. There are more factors which influence the magnitude of the current signal. One possibility is the development of a condensed layer during the exposition of the cell and dissolves the traces of ions completing the circuit [26]. The insulating material itself might dissolve the vapour thus contributing to the enhancement of conductivity. The solvation of ionic impurities can occur according to the following equilibrium process:

$\mathrm{AB} \longleftrightarrow \mathrm{A}_{(\text {sol) }}^{+}+\mathrm{B}^{-}{ }_{(\mathrm{sol})}$.

In the above equation $\mathrm{AB}$ denotes the electrolyte and subscript (sol) is related to the solvation of ions by the solvent molecules coming from the vapor phase. The equilibrium constant of the reaction strongly depends on the permittivity of the solvent as it is shifted to the dissociation by higher permittivities. So, magnitude of the signal is strongly influenced by the dielectric constant of the corresponding liquid.

The material of the insulating material between electrodes might also influence the detectability of the different vapors through its hydrophilicity or hydrophobicity.

The increase of conductivity needs several minutes as it is shown in Fig. 2 during exposure of the cell containing the bare carbon microdisc to acetic acid. As more time elapsed during exposition more and more steeper voltammograms could be obtained. The observed current increase in time is mainly due to the continuous dissolving of analyte in the insulating plastic material and development of condensed film. This process is the cell equilibration while it gets ready to give the steady state signal. The curves have an ohmic character as currents are 


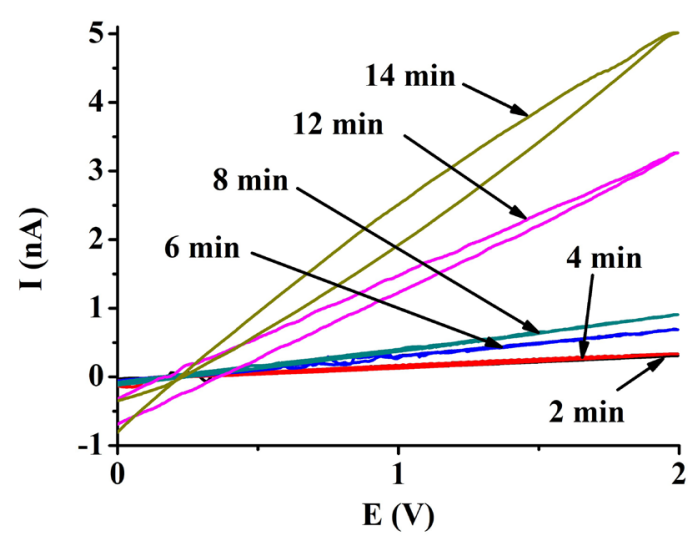

Fig. 2 Recorded cyclic voltammetric curves for acetic acid with the cell containing bare carbon microdisc

linearly proportional to the cell voltage similarly to earlier works with narrow-gap electrochemical cells.

Due to these observations and results found in the literature after all measurements the cell was regenerated as solvent vapors should be removed completely also from the insulating material and it needed some time. So, 30 minutes were allowed for analyte diffusion from the cell by keeping the cell at the ambient atmosphere.

As water content might interfere with the signals recorded for a volatile material, cyclic voltammetric responses to different humidities were measured with the cell containing the $\mathrm{Cu}_{\mathrm{x}} \mathrm{S}$ modified carbon microdisc. The relative humidity in Hungary can change between 30 and $90 \%$ according to the weather and it might change locally due to different human activities like drying of wet things, washing, boiling of water. An important feature of the electrochemical cell is how it responds to dry air. The inner space of a vessel was washed thoroughly with artificial air containing only $21 \%$ oxygen and $79 \%$ nitrogen. The gas was introduced into the vessel through a plastic tube which was inserted into the hole drilled into a Plexiglas sheet containing the electrochemical cell. The introduced gas flowed from the vessel through another hole. A voltammetric curve was also taken in the ambient air (relative humidity: $37 \%$ ). Furthermore, an additional curve was recorded in air with higher humidity $(64 \% \mathrm{RH})$. The latter condition was set by evaporating some water in a bigger closed volume containing the humidity meter. When it reached its steady state value the measurement was carried out. The air saturated with air (100\% RH) was prepared by placing some $\mathrm{cm}^{3}$ of water to the bottom of the vessel closed by the Plexiglas sheet containing the electrochemical cell. After equilibration ( 15 minutes) the voltammogram was taken.
Fig. 3 displays the recorded curves for the different humidities. As it can be seen there are subtle differences between currents measured in dry and ambient air. The measured humidity value $37 \%$ is characteristic for ambient conditions when the duration of dry weather is long. This fact is advantageous namely, the water content has negligible effect on the current signal when detection of organic volatile chemicals is aimed in atmosphere with lower humidity. The presenting water is insufficient to build up a coherent condensed film and significantly improve the conductivity. In more humid but not saturated atmospheres (64\% RH) a remarkable current increase develops by scanning the cell voltage to more and more positive values indicating that a very thin liquid film can build up on the interelectrode gap showing that water adsorbs readily on the surface of $\mathrm{Cu}_{\mathrm{x}} \mathrm{S}$. In conditions where the water content is significant, its interference should not be neglected. By use of amperometric and voltammetric techniques in air samples water interference is a problem at higher humidities independently on the electrode material. In air saturated with water $(100 \% \mathrm{RH})$ the signal increased drastically compared with the other conditions investigated (inset graph of Fig. 3). A coherent and thicker water layer covered the gap which permits the transport of ions.

As it was shown above the cell needs equilibration time before accomplishing comparative voltammetric measurements. So, cyclic voltammograms were taken with equilibrated cells which means that the cell was exposed to the vapor until the equilibrium between the liquid and gaseous phase could be reached (for 15 minutes). Fig. 1 shows the obtained cyclic voltammograms for the four compounds with bare and $\mathrm{Cu}_{\mathrm{x}} \mathrm{S}$ modified carbon electrode. In case of acetic acid (Fig. 4(a)), an ohmic behaviour could be

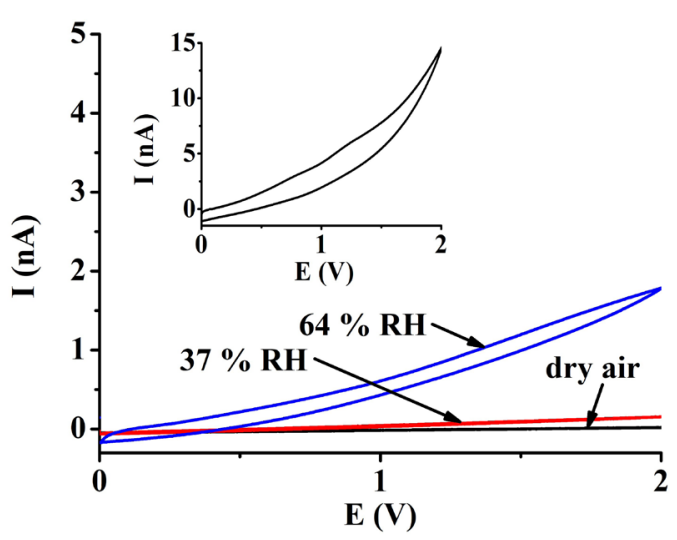

Fig. 3 Cyclic voltammograms taken with the cell containing the $\mathrm{Cu}_{\mathrm{x}} \mathrm{S}$ modified carbon microdisc in air by different humidities. Inset graph: voltammogram obtained at $100 \% \mathrm{RH}$. 
observed not only with bare but also with modified microelectrode. The reason for the continuous current increase is the oxidation on their-OH group resulting acyl radicals and during their dimerisation diacetyl peroxide forms as the following equation shows the electrochemical reaction:

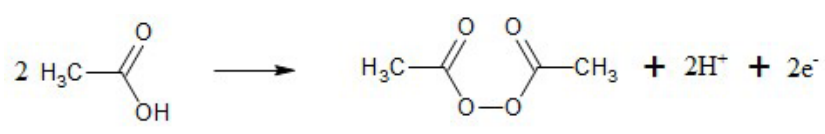

Charged species (protons) form at the anode which associate with neutral molecules and then, they migrate to the counter electrode. Due to this process, the ionic flow increases during the anodic polarisation across the gap. However, a portion of the formed product molecules can diffuse to the counter electrode and reduced back to analyte. The voltammogram obtained with sulphide modified electrode runs a little below the voltammogram recorded with the unmodified electrode indicating that the layer acts as a diffusion barrier.

Similar observations could be obtained in case of ethyl acetate (Fig. 4(b)) but it showed a very weak current increase compared with acetic acid. The reason for the observed current signals is the formation of a radical due to the oxidation of molecules on the ether oxygen [27] shown by the oxidation reaction:

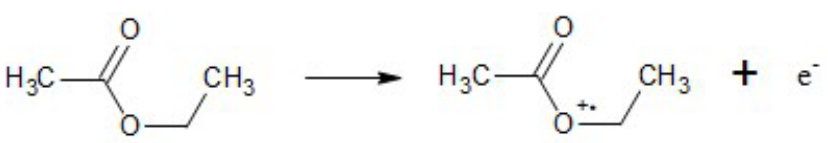

Few molecules react on the electrodes in the investigated. Therefore, the speed of charge generation is low and consequently the current increases slowly. This is the reason why the oxidation efficiency is still significantly low. The differences were more significant between the modified and unmodified electrode than in case of acetic acid. The voltammogram recorded with the modified microelectrode has a little curvature by keeping also the ohmic character. This latter observation suggest that adsorption of ethyl acetate is more favourable on the surface of $\mathrm{Cu}_{\mathrm{x}} \mathrm{S}$.

The modification with the sulphide layer resulted in a remarkable difference by investigating 2-propanol compared with the bare carbon microdisc (Fig. 4(c)). Using the unmodified electrode there was only small current increase $(5 \mathrm{nA})$ as it is shown in the inset graph. The electrooxidation of the alcohol produced acetone. At $1.2 \mathrm{~V}$ by measuring with the modified electrode there is a wide peak attributable to the adsorbed analyte molecules on $\mathrm{Cu}_{\mathrm{x}} \mathrm{S}$. It is a good electrocatalytic layer and it has also a porous structure which enhances significantly the electrochemically active surface area. These two properties make the sulphide layer very promising in detection of 2-propanol and alcohols as sufficiently higher currents can be recorded than with bare electrode. It is a significant improvement in sensitivity and seems to be useful by detection of alcoholic compounds in gaseous phase. As the $\mathrm{Cu}_{\mathrm{x}} \mathrm{S}$ is a semiconductor, its surface is appropriate for organic molecules to react in a rapid charge transfer and electrons flow to the carbon microdisc. Meanwhile, a very thin layer forms completing the circuit. Another advantage of surface modification with the $\mathrm{Cu}_{\mathrm{x}} \mathrm{S}$ layer is the large improvement of the signal to noise ratio as the influence of the external noise is negligible. In a work where narrow-gap voltammetric sensors were investigated [3], the exposure to ethanol was examined using carbon and the usual noble and less noble metal microelectrodes but some nA currents could be only reached. Moreover, in that study the potential was scanned to $8 \mathrm{~V}$ while in this study sufficiently higher currents were recorded between 0 and $2 \mathrm{~V}$ with the $\mathrm{Cu}_{\mathrm{x}} \mathrm{S}$ modifying layer. Comparing the magnitude of the signal with that of water displayed in an earlier section the sensitivity of the modified electrode to water and 2-propanol is very comparable.

Voltammetric curves of $n$-butylamine are depicted in Fig. 4(d). In case of the bare electrode the current increase is very fast also at mildly anodic potentials which is in accordance with that amines are susceptible to oxidation. The reaction is probably dehydrogenation whose product is 1-butylimine and/or butylnitrile [28]:

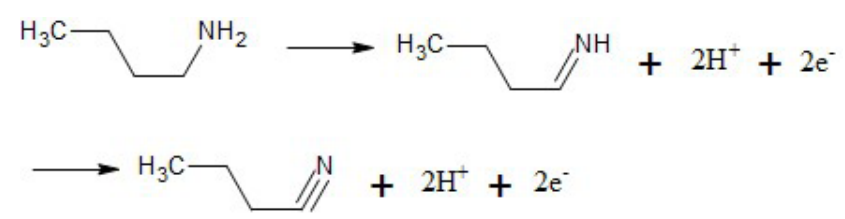

The related curve clearly shows that the bare carbon is very sensitive to this compound with maximum current of $\sim 11 \mathrm{nA}$ at $2 \mathrm{~V}$. It can be attributed to the thicker condensed film formed on the cell surface by bridging the interelectrode gap. The shape of the voltammograms is similar to that of the condensed phases having a wide oxidation peak centered around $1 \mathrm{~V}$. It can be explained by the destruction of the film adsorbed on the carbon microdisc. The additional current increase at higher potentials is rather because of the further decrease of the resistance in the condensed film. In contrary, significantly lower currents flowed in presence of the $\mathrm{Cu}_{\mathrm{x}} \mathrm{S}$ layer. However, the shape of the voltammogram is very similar to that of 

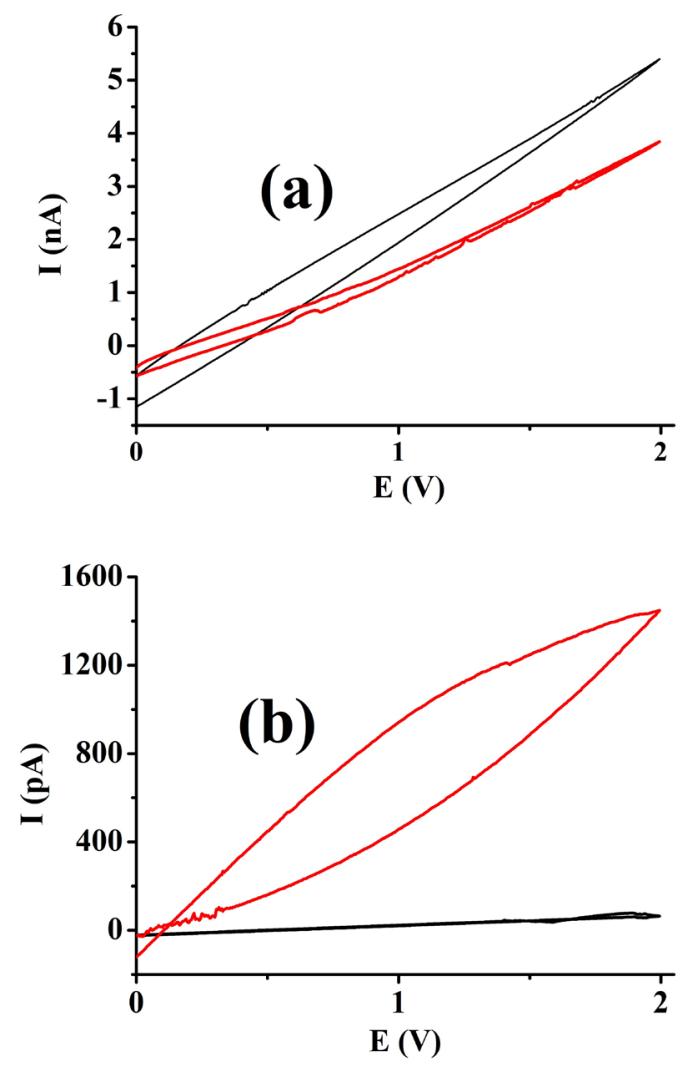
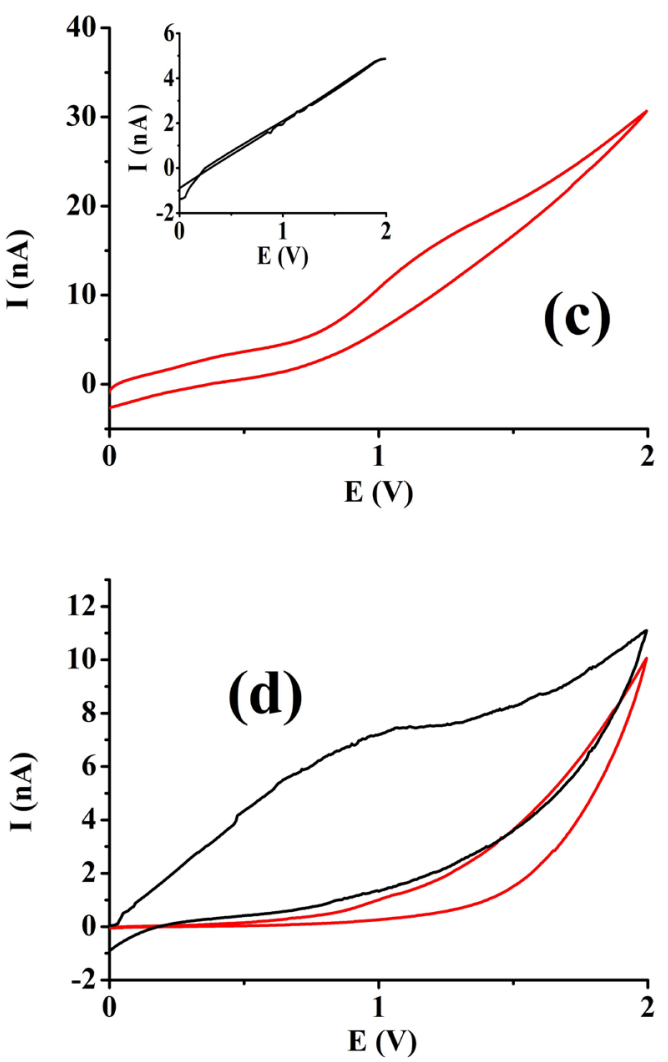

Fig. 4 Cyclic voltammograms of acetic acid (a), ethyl acetate (b), 2-propanol (c), and $n$-butylamine (d) in their saturated vapour phase. Red line: $\mathrm{Cu}_{\mathrm{x}} \mathrm{S}$ modified carbon microdisc, black line: bare carbon microdisc. Inset graph in (c) is related to the bare electrode.

bare electrode and the peak around $1 \mathrm{~V}$ also appeared, but the peak current decreased to the $\sim 13 \%$ of the value obtained with bare carbon microdisc. This observation shows evidently that the sulphide layer acts by $n$-butylamine as a strong diffusion barrier. On the other hand, the resistance of copper sulphides increases by exposing to ammonia and amines [16]. In case of amines, charge transfer processes are more inhibited at the surface of copper sulphide compared with carbon.

\subsection{Amperometric studies}

In practice, the response time is an important property of a sensor that is why it was also studied placing the cell into the saturated vapour phase above the volatile liquids. By using amperometric techniques an appropriate constant voltage is imposed to the cell and signal shows up during the exposition of a compound present in the gaseous phase. In the previous voltammetric studies some compounds showed ohmic behaviour and it was interesting to study the current change in time from starting the exposure when the working electrode is polarized to high anodic potential. The amperometric experiments were carried out setting $2 \mathrm{~V}$ constant working electrode potential and $1000 \mathrm{~s}$ was set as run time for a measurement. After starting an amperometric experiment, the cell was kept in the ambient atmosphere in the first 50 minutes to have a baseline. After this time the exposure tests started by placing the vessel quickly under the cell containing the pure liquid and the saturated vapor.

Fig. 5(a) shows the curves for acetic acid and it can be seen obviously that the current increases continuously in time in case of both bare and modified electrode. In presence of $\mathrm{Cu}_{\mathrm{x}} \mathrm{S}$ modifying layer remarkable current increase could be observed after an induction period elapsed from the beginning of exposure. This shows also the previously observed diffusion barrier type behaviour of the sulphide layer. After longer exposure time the curve measured with the modified electrode crosses the curve measured with bare electrode. At run times longer than $320 \mathrm{~s}$ the higher charge flow in case of modified carbon disc is mainly due to the enhanced active surface area.

The performance of the modified and unmodified carbon microelectrode is shown in Fig. 5(b) for ethyl acetate. In case of bare carbon electrode there is a very slow 

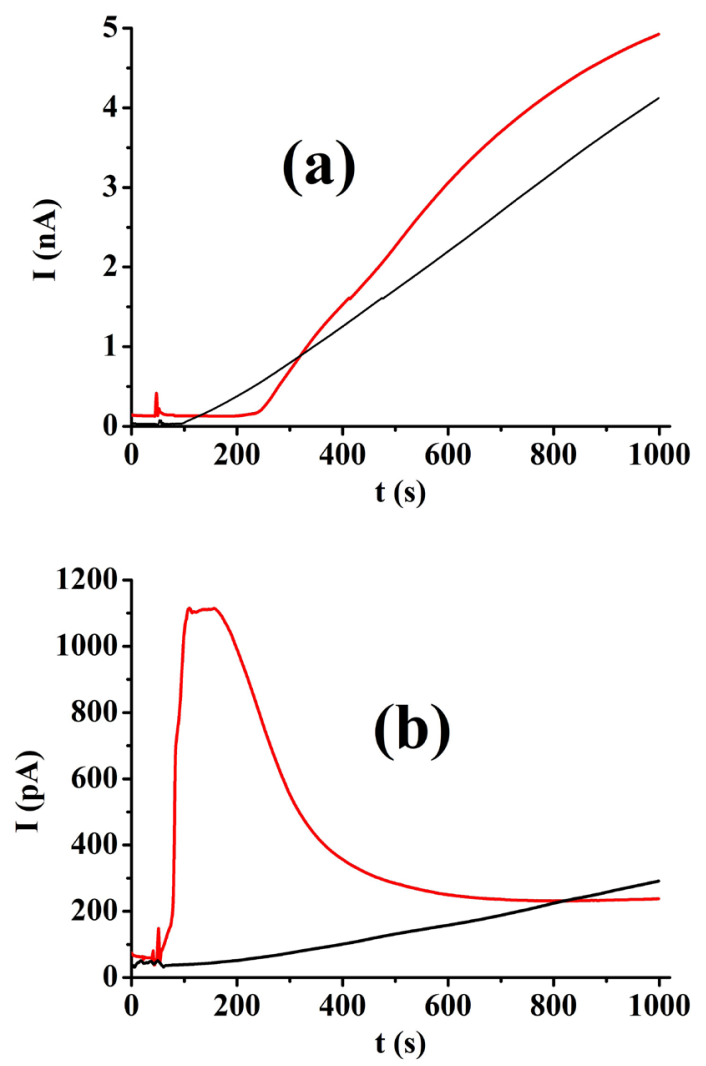
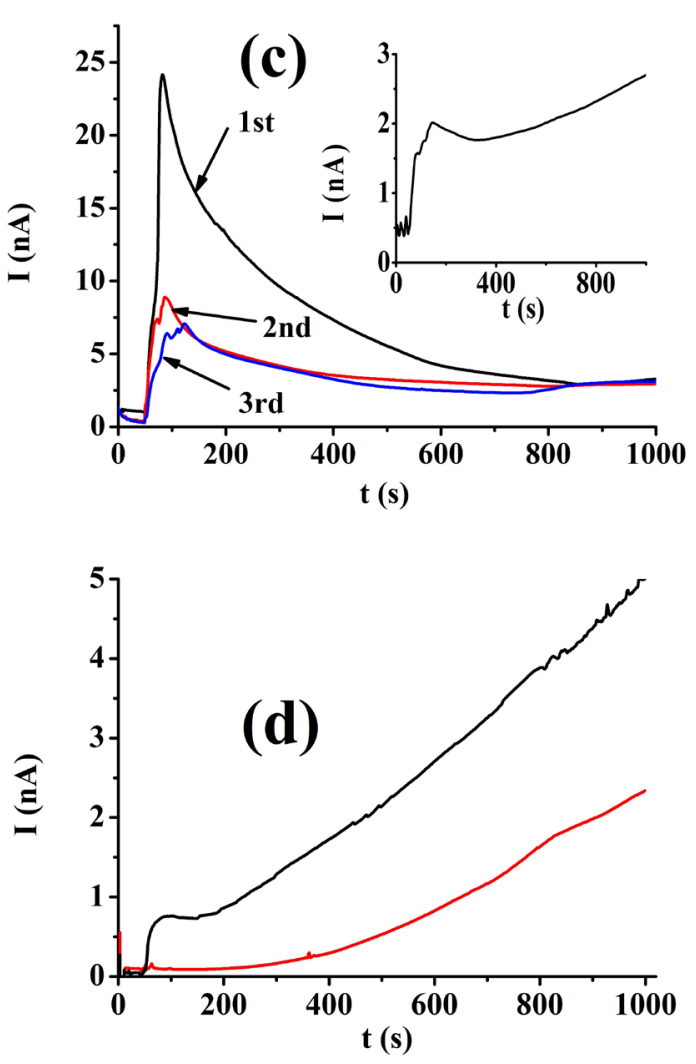

Fig. 5 Amperometric curves upon exposure of bare electrode (black line) and $\mathrm{Cu}_{\mathrm{x}} \mathrm{S}$ modified carbon microdisc electrode (red line) to acetic acid (a), ethyl acetate (b), and $n$-butylamine (d) in their saturated vapour phase ( $E=2 \mathrm{~V})$. Inset graph displays in Fig. 5(c) the current signal of the bare electrode. The curves in Fig. 5(c) are related to the modified electrode in case of 2-propanol.

current increase showing that this compound forms a very thin condensed layer at the gap as it could be observed in the voltammetric experiments. By studying the modified electrode at the beginning there was a small and fast current increase followed by a maximum. At longer times the decrease was also fast and then, the currents became similar to the currents of the bare electrode. The presence of maximum at a short exposure time suggests that the ethyl acetate molecules can adsorb in the pores of sulphide layer.

The really surprising results could be obtained for 2-propanol because in case of sulphide layer after beginning the exposure a very sharp increase verified its electrocatalytic property and has a maximum by nearly $24 \mathrm{nA}$ (Fig. 5(c)). Then, a current decay showed that the pores became saturated with alcohol molecules and they were oxidized. The shape of the decay suggests that the charge transfer process is diffusion controlled. The products prevented the analyte molecules to diffuse to the catalytic sites inside the pores and to the carbon surface. On the other hand, the significant increase in the current response was caused probably by the high quantity of adsorbed analyte due to the enhanced electroactive surface area. Because of the short response time and the significantly higher currents this modification can be useful by development of narrow-gap cells. The copper sulphide modified carbon electrode responds very quickly towards alcohols.

For 2-propanol repetitive exposure tests were carried out at $2 \mathrm{~V}$ and the related curves are also shown in Fig. 5(c). The maximum current of the second curve was significantly smaller and in the third amperometric experiment smaller currents could be detected than in the second one. The decreasing of the heights of the maxima appeared due to the accumulation of the oxidation products and the slopes of decays after the peaks are proportional to the maximum peak height by each curve. The cell was then left in the ambient atmosphere for twenty minutes. During this time oxidation product(s) could diffuse away from the electrode and the pores of $\mathrm{Cu}_{\mathrm{x}} \mathrm{S}$. A new amperometric curve was recorded after this time (not shown). Similarly, high current maximum showed up as in the first measurement indicating that the modified electrode was not irreversibly deactivated. The surface of the modifying layer 
can be renewed indicating the grateful performance of copper sulphide as electrode material.

The bare carbon electrode responded very rapidly by starting the exposure to the $n$-butylamine vapour as it can be seen in Fig. 5 d. The sharp current increase $(\sim 0.8 \mathrm{nA})$ by starting the exposure can be attributed to the rapid formation of a very thin condensed film on the cell surface. The currents are significantly lower than in the voltammetric experiments as there was no exposure before the anodic polarisation. The development of the condensed layer was very slow due to the low permittivity of the investigated amine $\left(\varepsilon_{r}=4.71\right)$. The equilibration of the cell to this compound needs a lot of time. In the earlier voltammetric experiments the obtained high current signal can be attributed to the insulating material. The bare surface was very easily accessible for the amine molecules. Due to this accumulation process, more and more analyte could be oxidized due to the continuous increasing of the conductivity of the condensed film. The diffusion barrier type behaviour of the $\mathrm{Cu}_{\mathrm{x}} \mathrm{S}$ layer is unambiguously emphasized also with the amperometric detection. After $50 \mathrm{sec}-$ onds from the beginning of anodic polarization the currents increased hardly and a slower current rising could be observed as a sign that more and more pores became wet and some time was necessary until the carbon surface could be reached. The bare carbon seems to be very useful to detect rapidly and sensitively the volatile amines so it might have higher practical interest.

\section{References}

[1] Ghoroghchian, J., Sarfarazi, F., Dibble, T., Cassidy, J., Smith, J. J., Russell, A., Dunmore, G., Fleischmann, M., Pons, S. "Electrochemistry in the gas phase. Use of ultramicroelectrodes for the analysis of electroactive species in gas mixtures", Analytical Chemistry, 58(11), pp. 2278-2282, 1986. https://doi.org/10.1021/ac00124a035

[2] Brina, R., Pons, S. "The use of narrow gap microelectrodes as sensitive and species selective gas chromatographic detectors", Journal of Electroanalytical Chemistry and Interfacial Electrochemistry, 264(1-2), pp. 121-130, 1989. https://doi.org/10.1016/0022-0728(89)80151-2

[3] Mosier-Boss, P. A., Lieberman, S. H. "Feasibility studies for the detection of volatile organic compounds in the gas phase using microelectrode sensors", Journal of Electroanalytical Chemistry, 460(1-2), pp. 105-118, 1999.

https://doi.org/10.1016/S0022-0728(98)00364-7

[4] Dibble, T., Bandyopadhyay, S., Ghoroghchian, J., Smith, J. J., Sarfarazi, F., Fleischmann, M., Pons, S. "Electrochemistry at very high potentials: oxidation of the rare gases and other gases in non-aqueous solvents at ultramicroelectrodes", Journal of Physical Chemistry, 90(21), pp. 5275-5277, 1986. https://doi.org/10.1021/j100412a075
The repeatability was investigated not only in case of 2-propanol but also with the other three compounds. The shape of the curves were very similar by each compounds but the magnitude of maximum currents changed significantly (about $\pm 10 \%$ around the average value).

\section{Conclusions}

In these experiments the $\mathrm{Cu}_{\mathrm{x}} \mathrm{S}$ modified carbon microelectrode was successfully tested in the detection of 2-propanol where significant increase in the sensitivity was achieved. These studies highlighted that $\mathrm{Cu}_{\mathrm{x}} \mathrm{S}$ has excellent properties to apply it as an electrode material in fabrication of voltammetric and amperometric sensors especially for alcoholic compounds. The results suggest also that the application of the $\mathrm{Cu}_{\mathrm{x}} \mathrm{S}$ modifying layer can gain further interest in electroanalytical chemistry in gas phase. It was also shown that application of an appropriate modifying layer can improve the sensitivity towards certain analytes apart from the width of interelectrode gap. Another advantage is that no expensive material is needed for making the $\mathrm{Cu}_{\mathrm{x}} \mathrm{S}$ layer which is stable during anodic oxidation.

\section{Acknowledgement}

The project has been supported by the European Union, co-financed by the European Social Fund Grant no.: EFOP-3.6.1.-16-2016-00004 entitled by Comprehensive Development for Implementing Smart Specialization Strategies at the University of Pécs.

[5] Maldonado, S., García-Berríos, E., Woodka, M. D., Brunschwig, B. S., Lewis, N. S. "Detection of organic vapors and $\mathrm{NH}_{3}(\mathrm{~g})$ using thin-film carbon black-metallophtalocyanine composite chemiresistors", Sensors and Actuators B: Chemical, 134(2), pp. 521-531, 2008.

https://doi.org/10.1016/j.snb.2008.05.047

[6] Lange, U., Mirsky, V. M. "Chemiresistors based on conducting polymers: A review on measurement techniques", Analytica Chimica Acta, 687(2), pp. 105-113, 2011.

https://doi.org/10.1016/j.aca.2010.11.030

[7] Jeong, H.-M., Kim, H.-J., Rai, P., Yoon, J.-W., Lee, J.-H. "Cr-doped $\mathrm{Co}_{3} \mathrm{O}_{4}$ nanorods as chemiresistor for ultrasensitive monitoring of methyl benzene", Sensors and Actuators B: Chemical, 201, pp. 482-489, 2014. https://doi.org/10.1016/j.snb.2014.05.038

[8] Alizadeh, T., Rezaloo, F. "A new chemiresistor sensor based on a blend of carbon nanotube, nano-sized molecularly imprinted polymer and poly methyl methacrylate for the selective and sensitive determination of ethanol vapour", Sensors and Actuators B: Chemical, 176, pp. 28-37, 2013. https://doi.org/10.1016/j.snb.2012.08.049 
[9] Jiang, Z., Jiang, T., Wang, J., Wang, Z., Xu, X., Wang, Z., Zhao, R., Li, Z., Wang, C. "Ethanol chemiresistor with enhanced discriminative ability from acetone based on $\mathrm{Sr}$-doped $\mathrm{SnO}_{2}$ nanofibers", Journal of Colloid and Interface Science, 437, pp. 252-258, 2015. https://doi.org/10.1016/j.jcis.2014.09.056

[10] Dobrokhotov, V., Oakes, L., Sowell, D., Larin, A., Hall, J., Kengne, A., Bakharev, P., Corti, G., Cantrell, T., Prakash, T., Williams, J., McIlroy, D. N. "Toward the nanospring-based artificial olfactory system for trace-detection of flammable and explosive vapors", Sensors and Actuators B: Chemical, 168, pp. 138-148, 2012. https://doi.org/10.1016/j.snb.2012.03.074

[11] Alizadeh, T., Soltani, L. H. "Graphene / poly(methyl methacrylate) chemiresistor sensor for formaldehyde odor sensing", Journal of Hazardous Materials, 248-249, pp. 401-406, 2013. https://doi.org/10.1016/j.jhazmat.2012.12.019

[12] Kannan, P. K., Saraswathi, R., Rayappan, J. B. B. "A highly sensitive humidity sensor based on DC reactive magnetron sputtered zinc oxide thin film", Sensors and Actuators A: Physical, 164(1-2), pp. 8-14, 2010. https://doi.org/10.1016/j.sna.2010.09.006

[13] Babaei, M., Alizadeh, N. "Methanol selective gas sensor based on nanostructured conducting polypyrrole prepared by electrochemically on interdigital electrodes for biodiesel analysis", Sensors and Actuators B: Chemical, 183, pp. 617-626, 2013. https://doi.org/10.1016/j.snb.2013.04.045

[14] Sagade, A. A., Sharma, R. "Copper sulphide $\left(\mathrm{Cu}_{x} \mathrm{~S}\right)$ as an ammonia gas sensor working at room temperature", Sensors and Actuators B: Chemical, 133(1), pp. 135-143, 2008. https://doi.org/10.1016/j.snb.2008.02.015

[15] Šetkus, A., Galdikas, A., Mironas, A., Strazdienė, V., Šimkienè, I., Ancutienė, I., Janickis, V., Kačiulis, S., Mattogno, G., Ingo, G. M. "The room temperature ammonia sensor based on improved $\mathrm{Cu}_{\mathrm{x}} \mathrm{S}$ micro-porous-Si structure", Sensors and Actuators B: Chemical, 78(1-3), pp. 208-215, 2001. https://doi.org/10.1016/S0925-4005(01)00814-0

[16] Galdikas, A., Mironas, A., Strazdienė, V., Šetkus, A., Ancutienė, I., Janickis, V. "Room-temperature-functioning ammonia sensor based on solid-state $\mathrm{Cu}_{\mathrm{x}} \mathrm{S}$ films", Sensors and Actuators B: Chemical, 67(1-2), pp. 76-83, 2000. https://doi.org/10.1016/S0925-4005(00)00408-1

[17] Ancutiene, I., Janickis, V., Ivanauskas, R. "Formation and characterisation of conductive thin layers of copper sulphide $\left(\mathrm{Cu}_{x} \mathrm{~S}\right)$ on the surface of polyethylene and polyamide by the use of higher polythionic acids", Applied Surface Science, 252(12), pp. 4218-4225, 2006. https://doi.org/10.1016/j.apsusc.2005.06.028

[18] Isac, L., Duta, A., Kriza, A., Manolache, S., Nanu, M. "Copper sulfides obtained by spray pyrolysis - Possible absorbers in solid-state solar cells", Thin Solid Films, 515(15), pp. 5755-5758, 2007. https://doi.org/10.1016/j.tsf.2006.12.073
[19] Chen, X., Wang, Z., Wang, X., Zhang, R., Liu, X., Lin, W., Qian, $\mathrm{Y}$. "Synthesis of novel copper sulphide hollow spheres generated from copper (II)-thiourea complex", Journal of Crystal Growth, 263(1-4), pp. 570-574, 2004.

https://doi.org/10.1016/j.jcrysgro.2003.12.004

[20] Nair, P. K., Cardoso, J., Gomez Daza, O., Nair, M. T. S. "Polyethersulphone foils as stable transparent substrates for conductive copper sulphide thin film coatings", Thin Solid Films, 401(1-2), pp. 243-250, 2001. https://doi.org/10.1016/S0040-6090(01)01629-7

[21] Raj, C. J., Kim, B. C., Cho, W.-J., Lee, W.-G., Seo, Y., Yu, K.-H. "Electrochemical capacitor behaviour of copper sulphide (CuS) nanoplatelets", Journal of Alloys and Compounds, 586, pp. 191-196, 2014. https://doi.org/10.1016/j.jallcom.2013.10.056

[22] Shih, Z.-Y., Periasamy, A. P., Hsu, P.-C., Chang, H.-T. "Synthesis and catalysis of copper sulphide / carbon nanodots for oxygen reduction in direct methanol fuel cells", Applied Catalysis B: Environmental, 132-133, pp. 363-369, 2013. https://doi.org/10.1016/j.apcatb.2012.12.004

[23] Yang, Y. J., Li, W., Zi, J. "Mechanistic study of glucose oxidation on copper sulphide modified glassy carbon electrode", Electrochemistry Communications, 34, pp. 304-307, 2013. https://doi.org/10.1016/j.elecom.2013.07.012

[24] Bo, X., Bai, J., Wang, L., Guo, L. "In situ growth of copper sulphide nanoparticles on ordered mesoporous carbon and their application as nonenzymatic amperometric sensor of hydrogen peroxide", Talanta, 81(1-2), pp. 339-345, 2010. https://doi.org/10.1016/j.talanta.2009.12.007

[25] Kiss, L., Nagy, G., Kovács, B. "Amperometric Response of Alcohols Dissolved in High Resistance Hydrocarbon Media at Microelectrodes Without Supporting Electrolyte", Electroanalysis, 24(11), pp. 2117-2124, 2012. https://doi.org/10.1002/elan.201200261

[26] Fang, Y., Leddy, J. "Voltammetry in gas phase environments", Journal of Electroanalytical Chemistry, 384(1-2), pp. 5-17, 1995. https://doi.org/10.1016/0022-0728(94)03728-L

[27] Pailleret, A., Arrigan, D. W. M. "Electrochemical oxidation of a tetraester calix[4]arene", Electrochemistry Communications, 3(1), pp. 24-27, 2001. https://doi.org/10.1016/S1388-2481(00)00142-9

[28] Łuczak, T. "Structure-reactivity relationships: the oxidation of aliphatic amines on the gold electrode", Journal of Applied Electrochemistry, 37(2), pp. 269-274, 2007. https://doi.org/10.1007/s10800-006-9253-5 